\title{
The Association between 25-Hydroxyvitamin D and Hemoglobin A1c Levels in Patients with Type 2 Diabetes and Stage 1-5 Chronic Kidney Disease
}

\author{
Farshad Kajbaf, ${ }^{1,2}$ Romuald Mentaverri, ${ }^{2,3}$ Momar Diouf, ${ }^{4}$ Albert Fournier, ${ }^{5}$ \\ Said Kamel, ${ }^{3}$ and Jean-Daniel Lalau ${ }^{1,2}$ \\ ${ }^{1}$ Department of Endocrinology and Nutrition, University Hospital of Amiens, 80054 Amiens, France \\ ${ }^{2}$ INSERM Unit 1088, Jules Verne University of Picardie, 80037 Amiens, France \\ ${ }^{3}$ Bone Biology and Endocrine Division, University Hospital of Amiens, 80054 Amiens, France \\ ${ }^{4}$ Clinical Research Center, University Hospital of Amiens, 80054 Amiens, France \\ ${ }^{5}$ Department of Clinical Nephrology, University Hospital of Amiens, 80054 Amiens, France
}

Correspondence should be addressed to Jean-Daniel Lalau; lalau.jean-daniel@chu-amiens.fr

Received 28 May 2014; Revised 18 July 2014; Accepted 14 August 2014; Published 27 August 2014

Academic Editor: Andreas Tomaschitz

Copyright (C) 2014 Farshad Kajbaf et al. This is an open access article distributed under the Creative Commons Attribution License, which permits unrestricted use, distribution, and reproduction in any medium, provided the original work is properly cited.

\begin{abstract}
Aim. To examine the relationship between plasma 25-hydroxyvitamin D (25(OH)D) levels and blood hemoglobin Alc (HbAlc) levels in diabetic patients at various stages of chronic kidney disease (CKD). Methods. We screened for data collected between 2003 and 2012. The correlation between $25(\mathrm{OH}) \mathrm{D}$ and $\mathrm{HbAlc}$ levels was studied in patients categorized according to the severity of CKD and their vitamin D status. A multivariate linear regression model was used to determine whether 25(OH)D and HbAlc levels were independently associated after adjustment for a number of covariates (including erythrocyte metformin levels). Results. We identified 542 reports from 245 patients. The mean $\mathrm{HbAlc}$ value was $6.7 \pm 1.0 \%$ in vitamin $\mathrm{D}$ sufficiency, $7.3 \pm 1.5 \%$ in insufficiency, and $8.4 \pm 2.0 \%$ in deficiency $(P<0.0001)$. There was a negative correlation between $25(\mathrm{OH}) \mathrm{D}$ and HbAlc levels for the population as a whole $(r=-0.387, P<0.0001)$ and in the CKD severity subgroups $(r=-0.384, P<0.0001$ and $r=-0.333, P<0.0001$ for CKD stages 1-3 and 4-5, resp.). In the multivariate analysis, the $25(\mathrm{OH}) \mathrm{D}$ level was the only factor associated with $\mathrm{HbAlc}(P<0.0001)$. Conclusion. 25(OH)D levels were negatively correlated with HbAlc levels independently of study covariates.
\end{abstract}

\section{Introduction}

In addition to the pivotal role of vitamin $\mathrm{D}$ in calcium/phosphorus homeostasis and bone physiology $[1,2]$, several lines of evidence suggest that vitamin D status may also have a significant role in glucose homeostasis in general [3] and on pathophysiology and progression of metabolic syndrome and Type 2 diabetes in particular [4]. Studies in animals and humans suggest that vitamin $\mathrm{D}$ affects insulin secretion and tyrosine phosphorylation of the insulin receptor [3]. Low levels of serum 25-hydroxyvitamin D (25(OH)D) were associated with surrogate measures of insulin resistance, major adverse cardiovascular events, cancers, and all-cause mortality, at least in subjects with metabolic syndrome [5]. Conversely, elevated 25(OH)D levels were associated with a lower risk of incident diabetes [6, 7]. Moreover, it has been reported that most patients with Type 2 diabetes have low 25(OH)D levels and that hemoglobin Alc (HbAlc) levels are negatively correlated with vitamin D status [8].

In view of the above findings, one can hypothesize that vitamin $\mathrm{D}$ supplementation decreases insulin resistance and reduces HbAlc levels in patients with diabetes. However, supplementation studies have not unambiguously found that vitamin $\mathrm{D}$ favors an improvement in glucose homeostasis parameters [9]. As it is well known that ageing and chronic kidney disease (CKD) are associated with changes in vitamin $\mathrm{D}$ metabolism and insulin resistance $[10,11]$, these studies would have been enriched by taking into account the impact of a number of factors on glucose metabolism, such as age, renal status, and antidiabetic medications but to name a few. 
In this regard, antidiabetic medications obviously impact insulin resistance (either directly or indirectly via the reduction in blood glucose levels). In this context, it seems essential to consider the role of metformin (the most frequently prescribed drug to patients with Type 2 diabetes mellitus [12]) in CKD for several reasons: (i) metformin is only contraindicated in severe CKD because it clears four to five times more quickly than creatinine [13], (ii) metformin's impressive cardiovascular protective effects should be of particular value in patients with CKD (who therefore have a high cardiovascular risk) [14], (iii) metformin therapy can potentially be continued in severe CKD as long as the latter one is stable and the dose of metformin is adjusted as a function of the severity of kidney disease [15], (iv) assaying for blood metformin should minimize the risk of metformin accumulation, (v) metformin accumulation is not dangerous per se [16], and (vi) metformin may even be protective in lactic acidosis caused by concomitant conditions [17].

In our institution, we continue metformin administration beyond the limit stated in the current guidelines by applying a pragmatic metformin dose reduction in our patients with low estimated glomerular filtration rate (eGFR) [18]. This provided us with an opportunity to study the relationship between 25(OH)D and HbAlc levels after adjusting for some covariates (including eGFR and erythrocyte metformin levels, the latter one better reflecting potential metformin accumulation than plasma metformin concentrations [19]).

\section{Methods}

2.1. Selection of Study Subjects. We systematically reviewed the medical records of all patients with Type 2 diabetes on metformin consulting in our university medical center between 2003 and 2012 (erythrocyte metformin assays were introduced in 2003). In general, the metformin assays had been requested in order to adjust the dose to the patient's renal status or to screen for metformin accumulation [18].

2.2. Collection of Biochemical Data. We selected patients for whom data on serum creatinine (to calculate estimated glomerular filtration rate), serum HbAlc, plasma 25(OH)D, and erythrocyte metformin levels were available.

Due to the half-life of vitamin D (of 2-3 weeks, [2]), we only considered HbAlc and metformin samples collected no more than two weeks before or two weeks after the $25(\mathrm{OH}) \mathrm{D}$ sample. If several HbAlc and metformin samples had been collected during this four-week interval, we selected those closest in time to the $25(\mathrm{OH}) \mathrm{D}$ sample. Likewise, and in view of the close relationship between blood metformin levels and renal status [18], we selected serum creatinine samples collected as close as possible to the metformin sample (and no more than one week before or one week after).

2.3. Estimation of the GFR. The eGFR was estimated according to the Modification of Diet in Renal Disease equation, which includes four variables: eGFR $(\mathrm{mL} / \mathrm{min}$ per $\left.1.73 \mathrm{~m}^{2}\right)=175 \times(\text { serum creatinine })^{-1.154} \times(\text { Age })^{-0.203} \times$ $(0.742$ if female $) \times(1.212$ if African-American) (conventional units) [20]. The patients were then classified into five CKD stages: $>90 \mathrm{~mL} / \mathrm{min}$ per $1.73 \mathrm{~m}^{2}$ (CKD stage 1 ), from 90 to $60 \mathrm{~mL} / \mathrm{min}$ per $1.73 \mathrm{~m}^{2}$ (CKD stage 2), from 60 to $30 \mathrm{~mL} / \mathrm{min}$ per $1.73 \mathrm{~m}^{2}$ (CKD stage 3), from 30 to $15 \mathrm{~mL} / \mathrm{min}$ per $1.73 \mathrm{~m}^{2}$ (CKD stage 4 ), and $<15 \mathrm{~mL} / \mathrm{min}$ per $1.73 \mathrm{~m}^{2}$ (CKD stage 5 ).

2.4. Data Analyses. After classification by CKD stage, the patients were also divided as a function of their vitamin D status: sufficiency (plasma $25(\mathrm{OH}) \mathrm{D} \geq 30 \mathrm{ng} / \mathrm{mL}$ ), insufficiency (21-29 ng/mL), and deficiency (i.e., $\leq 20 \mathrm{ng} / \mathrm{mL}$ ) [21]. A multivariate analysis was performed to establish whether or not there was an independent relationship between vitamin $\mathrm{D}$ status and HbAlc levels after adjusting a priori for age, gender, renal status, and erythrocyte metformin levels.

2.5. Analytical Methods. Creatinine levels were measured using a colorimetric assay. $25(\mathrm{OH}) \mathrm{D}$ levels were determined using chemiluminometric immunoassays (Liaison $25(\mathrm{OH})$ Vitamin D Total CLIA, which measures both $\mathrm{D}_{2}$ and $\mathrm{D}_{3}$; Diasorin, Stillwater, MN; CV: 6.1\%). An ion-exchange chromatography method (Variant II Turbo, Bio-Rad, Hercules, CA) was used to assay HbAlc, according to the manufacturer's instructions. Metformin levels were measured in duplicate in the same laboratory using reverse-phase highperformance liquid chromatography with diode-array detection, according to the method described by Lacroix et al. [22].

The erythrocyte level measurement technique has been described in detail elsewhere [19]. The results are expressed as the concentration of basic metformin. The assay's limit of detection was $0.03 \mathrm{mg} / \mathrm{L}$.

2.6. Statistical Analysis. For the groups of patients at each CKD stage, the mean \pm standard deviation (SD) of $25(\mathrm{OH}) \mathrm{D}$, HbAlc, erythrocyte metformin levels, and age was calculated. The demographic characteristics of the various CKD stages and vitamin D status groups were compared in an analysis of variance (ANOVA). The correlation between $25(\mathrm{OH}) \mathrm{D}$ and HbAlc levels was studied in the whole study population and in two separate subgroups of patients with nonsevere CKD (stages 1-3) or severe CKD (stages 4-5) by determining the coefficient of correlation $r$. A multivariate linear regression model with backward selection was used to assess the independence of the association between $25(\mathrm{OH}) \mathrm{D}$ and $\mathrm{HbAlc}$ levels after adjustment for other study variables.

The threshold for statistical significance was set to $P \leq$ 0.05. All statistical analyses were performed with SAS software (version 9.2, SAS Institute Inc., Cary, NC).

\section{Results}

3.1. Demographic and Clinical Characteristics. We identified a total of 542 reports in 245 patients meeting the selection criteria (mean \pm SD age: $65 \pm 11$; male/female gender $342 / 200,63 \% / 37 \%$ ), of whom 80 had 2 or more blood samples during a regular monitoring with a mean interval of 10 months. Patients enrolled in this study did not receive 1,25dihydroxyvitamin D3 (or one of its active analogs). The population's main demographic and clinical characteristics 
TABLE 1: Characteristics of the study patients (mean \pm standard deviation, $P$ value in an ANOVA).

\begin{tabular}{|c|c|c|c|c|c|c|c|}
\hline Status & $\begin{array}{l}\text { Number of } \\
\text { reports, } \\
(\%)\end{array}$ & $\begin{array}{l}\text { Age, } \\
\text { years }\end{array}$ & $\begin{array}{c}\text { eGFR, } \\
\mathrm{mL} / \mathrm{min} \text { per } \\
1.73 \mathrm{~m}^{2}\end{array}$ & $\begin{array}{c}\text { HbAlc, } \\
(\%)\end{array}$ & $\begin{array}{c}25(\mathrm{OH}) \mathrm{D} \\
\mathrm{ng} / \mathrm{mL}\end{array}$ & $\begin{array}{c}25(\mathrm{OH}) \mathrm{D} \\
>30 \mathrm{ng} / \mathrm{mL} \\
\%\end{array}$ & $\begin{array}{c}\text { Erythrocyte } \\
\text { metformin, } \\
\mathrm{mg} / \mathrm{L}\end{array}$ \\
\hline All reports & 542 & $65.0 \pm 11.2$ & $44.3 \pm 23.8$ & $7.6 \pm 1.8$ & $25.7 \pm 18.3$ & 34.7 & $1.43 \pm 1.45$ \\
\hline \multicolumn{8}{|l|}{ By CKD stage: } \\
\hline Stage 1 & $27(5.0)$ & $59.9 \pm 12.6$ & $103.9 \pm 11.1$ & $7.5 \pm 1.6$ & $19.7 \pm 15.9$ & 22.2 & $0.91 \pm 0.60$ \\
\hline Stage 2 & 95 (17.5) & $63.4 \pm 12.0$ & $72.0 \pm 8.7$ & $7.9 \pm 1.9$ & $22.7 \pm 16.3$ & 28.6 & $1.06 \pm 0.61$ \\
\hline Stage 3 & $268(49.4)$ & $66.8 \pm 10.1$ & $42.9 \pm 8.3$ & $7.8 \pm 1.9$ & $23.6 \pm 16.8$ & 30.6 & $1.31 \pm 0.92$ \\
\hline Stage 4 & 105 (19.4) & $66.3 \pm 2.0$ & $22.3 \pm 4.3$ & $7.4 \pm 1.4$ & $28.7 \pm 19.2$ & 39.0 & $1.68 \pm 1.99$ \\
\hline Stage 5 & $47(8.7)$ & $57.8 \pm 10.9$ & $9.3 \pm 3.1$ & $6.3 \pm 1.2$ & $40.6 \pm 21.6$ & 68.1 & $2.58 \pm 2.78$ \\
\hline$P$ value & - & $P<0.0001$ & $P<0.0001$ & $P<0.0001$ & $P<0.0001$ & $P<0.0001$ & $P<0.0001$ \\
\hline \multicolumn{8}{|c|}{ By vitamin D status: } \\
\hline Sufficiency & $188(34.7)$ & $65.6 \pm 10.9$ & $38.3 \pm 23.1$ & $6.7 \pm 1.0$ & $45.9 \pm 14.9$ & - & $1.39 \pm 0.97$ \\
\hline Insufficiency & $109(20.1)$ & $63.4 \pm 11.6$ & $42.5 \pm 22.4$ & $7.3 \pm 1.5$ & $24.8 \pm 2.7$ & - & $1.31 \pm 0.87$ \\
\hline Deficiency & $245(45.2)$ & $65.3 \pm 11.3$ & $49.6 \pm 23.8$ & $8.4 \pm 2.0$ & $10.7 \pm 4.8$ & - & $1.51 \pm 1.89$ \\
\hline$P$ value & - & NS & $P<0.0001$ & $P<0.0001$ & $P<0.0001$ & - & NS \\
\hline
\end{tabular}

(including the proportions of patients at CKD stages 1 to 5) are summarized in Table 1.

About $50 \%$ of the patients were at CKD stage 3. Stage 5 patients differed significantly from stage 1-4 patients: they were younger, with a lowest mean $\mathrm{HbAlc}$ value, a much higher mean 25(OH)D level (around twice that of stage 1 patients), and a much higher mean erythrocyte metformin level (two or threefold greater than in the other subgroups) $(P<0.0001)$. Only 3 patients were on dialysis in this group.

3.2. Vitamin D and HbAlc Status. The vitamin D status study groups differed significantly in terms of the eGFR, HbAlc, and $25(\mathrm{OH}) \mathrm{D}$ values. These results are in accordance with those obtained from the CKD groups. The group with vitamin $\mathrm{D}$ sufficiency had the lowest mean $\mathrm{HbAlc}$ value.

The mean HbAlc values were $8.4 \pm 2.0 \%$ in the subgroup with vitamin deficiency, $7.3 \pm 1.5 \%$ in the "insufficiency" group, and $6.7 \pm 1.0 \%$ in the "sufficiency" group $(P<0.0001)$.

3.3. Correlation Studies and Multivariate Analysis. There was a negative correlation between $25(\mathrm{OH}) \mathrm{D}$ and $\mathrm{HbAlc}$ levels for the study population as a whole $(r=-0.387, P<0.0001)$ and in the CKD severity subgroups $(r=-0.384, P<0.0001$ and $r=-0.333, P<0.0001$ for CKD stages $1-3$ and $4-5$, resp.) (Figure 1).

In a multivariate analysis, the $25(\mathrm{OH}) \mathrm{D}$ level was the only factor independently associated with $\mathrm{HbAlc}$ after controlling for other study variables, $(P<0.0001)$.

\section{Discussion}

In accordance with previous studies [23-26], our present results revealed a significant, negative correlation between $25(\mathrm{OH}) \mathrm{D}$ levels and HbAlc values. However, the presence of a correlation does not necessarily mean that vitamin $\mathrm{D}$ has a positive impact on glucose homeostasis. Indeed, various factors may influence the relationship between vitamin $D$ and HbAlc. One of the strengths of the present study is inclusion of covariates in the analysis of the association between $25(\mathrm{OH}) \mathrm{D}$ and HbAlc. It is well known that some of these covariates (age, gender, and renal status) are influencing vitamin D status [27]. Here, we further refined the analysis of the association between vitamin $\mathrm{D}$ and HbAlc by taking account of erythrocyte metformin levels, since (i) the latter one may rise as renal function declines and (ii) this drug is known to influence HbAlc levels [28].

Although the ANOVA revealed a significant difference in the age between the CKD stage subgroups $(P<0.0001)$, most of the study population was middle-aged or elderly (under 70). Most of the patients had moderate to severe CKD (with around $75 \%$ at stages 3 to 5 ). On average, CKD stage 5 patients were younger than other CKD groups (e.g., almost ten years younger than the CKD stage 4 group), suggesting that the onset of CKD had occurred earlier in life in the CKD stage 5 patients.

It is noteworthy that the mean HbAlc value was lower in CKD stage 5 patients than in CKD stage $1-4$ patients $(6.3 \%$ and $7.5 \%$, resp.). This difference must be considered in the light of $25(\mathrm{OH}) \mathrm{D}$ levels: the mean $25(\mathrm{OH}) \mathrm{D}$ values in the population as a whole and in the CKD stage 1-4 patients were around $25 \mathrm{ng} / \mathrm{mL}$ (corresponding to insufficiency), whereas the value in CKD stage 5 patients was almost twice as high $(40.6 \mathrm{ng} / \mathrm{mL}$, corresponding to sufficiency). In other words, the CKD stage 5 patients had a particular profile, with an HbAlc value below $6.5 \%$ and the absence of vitamin $\mathrm{D}$ insufficiency. The results are satisfying from a clinical viewpoint and may reflect our policy of monitoring vitamin $\mathrm{D}$ status in patients with severe CKD (one of us (AF) has systematically used 25-OH vitamin D (cholecalciferol, $100000 \mathrm{U}$ every trimester) for early preventive treatment of secondary hyperparathyroidism in CKD stages 3-5). These observations may suggest a beneficial effect of vitamin D on HbAlc levels. The significantly greater erythrocyte metformin 


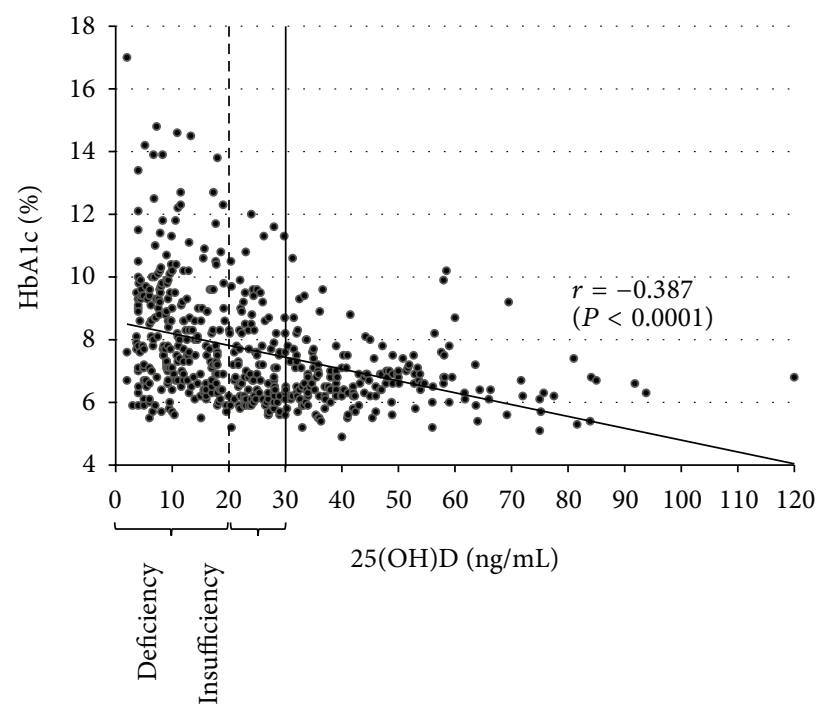

(a) All CKD stages

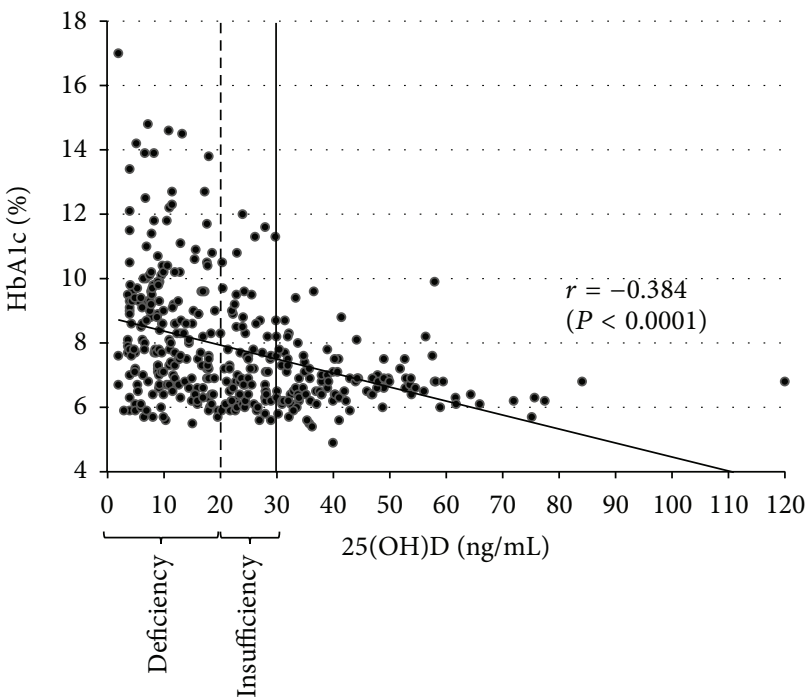

(b) CKD stages 1-3

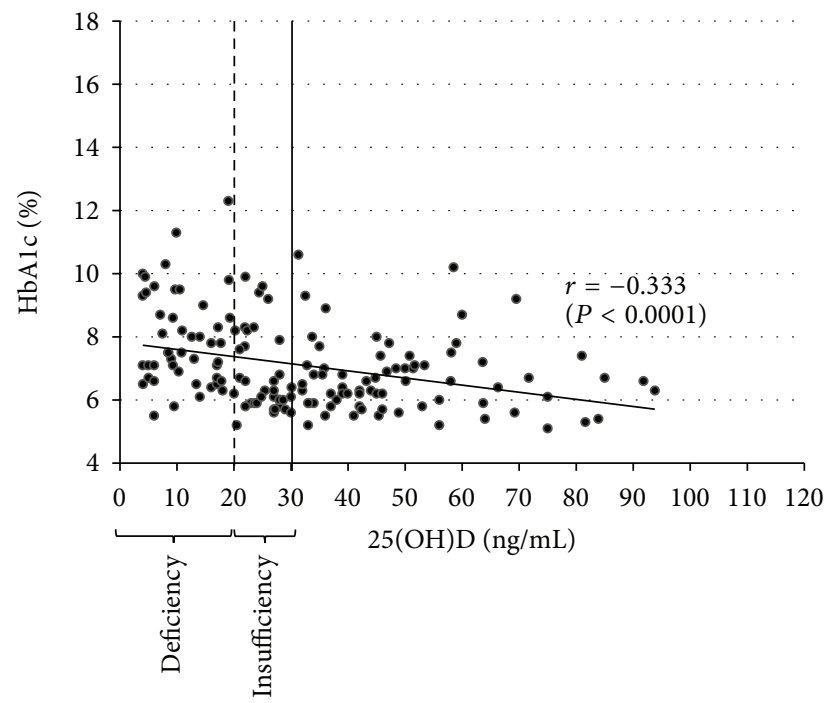

(c) CKD stages 4-5

Figure 1: The correlation between 25-hydroxyvitamin D and HbAlc levels in patients with Type 2 diabetes at various stages of chronic kidney disease (correlation coefficient $r$ ).

levels in CKD stage 5 patients were taken into account by our multivariate analysis. Consequently, favorable vitamin D status cannot be related to high blood erythrocyte metformin levels. Furthermore, we did not observe any correlation between HbAlc and metformin levels.

However, there are several possible difficulties when seeking to accurately assess long-term glycaemic status according to the HbAlc level in severe CKD: (i) severe CKD is characterized by peripheral insulin resistance [29]; (ii) HbAlc can be carbamylated by isocyanic acid (a reactive form of cyanate formed by the spontaneous dissociation of urea) [30]; and (iii) lifespan of erythrocytes is shortened by up to around onethird in haemodialysis patients [31], due to a combination of factors (vitamin deficiencies, iron deficiency, inflammation [32], the toxic uremic milieu [31], defective synthesis and secretion of erythropoietin [33], and hemolysis [31]). Taken as a whole, these factors may lead to underestimation of the HbAlc level.

Hence, our study results show that despite the presence of insulin resistance, $\mathrm{HbAlc}$ levels were the lowest in severe CKD. The carbamylation process did not impact the glycation of HbAlc, as measured by our method [30]. The shortened lifespan of erythrocytes may be a critical factor. Indeed, the $\mathrm{HbAlc}$ level was lower in severe CKD than in earlier stages. Nevertheless, it is important to note that the correlation coefficients in the severe CKD and the nonsevere CKD subgroups were almost exactly the same.

The present study had four limitations: (i) the effect of vitamin $\mathrm{D}$ on glucose metabolism was not studied directly, (ii) the study was retrospective, (iii) the relatively small 
number of patients in CKD stages 1 and 5, and (iv) the possible impact of antidiabetic agents other than metformin was not taken into account (although these agents are harder to be assayed in blood than metformin).

\section{Conclusion}

In diabetic patients, at various CKD stages, 25(OH)D levels were negatively correlated with HbAlc values. This association persisted after controlling for covariates such as age, gender, and erythrocyte metformin levels. These covariates must be taken into account when studying the effect of vitamin $D$ supplementation on glucose metabolism in randomized trials.

\section{Abbreviations}

\author{
25(OH)D: 25-hydroxyvitamin D \\ HbAlc: Hemoglobin \\ CKD: Chronic kidney disease \\ eGFR: $\quad$ Estimated glomerular filtration rate.
}

\section{Conflict of Interests}

The authors do not have any conflict of interest related to this paper.

\section{Authors' Contribution}

F. Kajbaf screened, extracted, and analyzed the data and wrote the paper; R. Mentaverri performed biological analyses and contributed to the discussion; M. Diouf performed statistics; A. Fournier provided the rationale of the study; S. Kamel contributed to the discussion; J. D. Lalau contributed to the discussion and wrote and reviewed the paper.

\section{References}

[1] A. S. Dusso, A. J. Brown, and E. Slatopolsky, "Vitamin D," American Journal of Physiology, vol. 289, no. 1, pp. F8-F28, 2005.

[2] M. F. Holick, "Vitamin D status: measurement, interpretation, and clinical application," Annals of Epidemiology, vol. 19, no. 2, pp. 73-78, 2009.

[3] M. Flores, "A role of vitamin D in low-intensity chronic inflammation and insulin resistance in type 2 diabetes mellitus?" Nutrition Research Reviews, vol. 18, no. 2, pp. 175-182, 2005.

[4] G. N. Thomas, B. Ó. Hartaigh, J. A. Bosch et al., "Vitamin D levels predict all-cause and cardiovascular disease mortality in subjects with the metabolic syndrome: the Ludwigshafen risk and cardiovascular health (LURIC) study," Diabetes Care, vol. 35, no. 5, pp. 1158-1164, 2012.

[5] K. C. Chiu, A. Chu, V. L. W. Go, and M. F. Saad, "Hypovitaminosis $\mathrm{D}$ is associated with insulin resistance and $\beta$ cell dysfunction," The American Journal of Clinical Nutrition, vol. 79, no. 5, pp. 820-825, 2004.

[6] C. Gagnon, Z. X. Lu, D. J. Magliano et al., "Serum 25-hydroxyvitamin $\mathrm{D}$, calcium intake, and risk of type 2 diabetes after 5 years: results from a national, population-based prospective study (the Australian diabetes, obesity and lifestyle study)," Diabetes Care, vol. 34, no. 5, pp. 1133-1138, 2011.
[7] A. G. Pittas, D. M. Nathan, J. Nelson et al., "Plasma 25-hydroxyvitamin $\mathrm{D}$ and progression to diabetes in patients at risk for diabetes: An ancillary analysis in the diabetes prevention program," Diabetes Care, vol. 35, no. 3, pp. 565-573, 2012.

[8] S. Pilz, K. van den Hurk, G. Nijpels et al., "Vitamin D status, incident diabetes and prospective changes in glucose metabolism in older subjects: the Hoorn study," Nutrition, Metabolism and Cardiovascular Diseases, vol. 22, no. 10, pp. 883-889, 2012.

[9] P. S. George, E. R. Pearson, and M. D. Witham, "Effect of vitamin D supplementation on glycaemic control and insulin resistance: a systematic review and meta-analysis," Diabetic Medicine, vol. 29, no. 8, pp. e142-e150, 2012.

[10] S. Williams, K. Malatesta, and K. Norris, "Vitamin D and chronic kidney disease," Ethnicity \& Disease, vol. 19, supplement 5, pp. 8-11, 2009.

[11] A. M. Hung and T. A. Ikizler, "Factors determining insulin resistance in chronic hemodialysis patients," Contributions to Nephrology, vol. 171, pp. 127-134, 2011.

[12] D. R. Erlich, D. C. Slawson, and A. Shaughnessy, "Diabetes update: new drugs to manage type 2 diabetes," FP essentials, vol. 408, pp. 20-24, 2013.

[13] A. J. Scheen, "Clinical pharmacokinetics of metformin," Clinical Pharmacokinetics, vol. 30, no. 5, pp. 359-371, 1996.

[14] S. El Messaoudi, G. A. Rongen, and N. P. Riksen, "Metformin therapy in diabetes: the role of cardioprotection," Current atherosclerosis reports, vol. 15, no. 4, article 314, 2013.

[15] F. Kajbaf, P. Arnouts, M. de Broe, and J. D. Lalau, "Metformin therapy and kidney disease: a review of guidelines and proposals for metformin withdrawal around the world," Pharmacoepidemiology and Drug Safety, vol. 22, pp. 1027-1035, 2013.

[16] J. Lalau, "Lactic acidosis induced by metformin: incidence, management and prevention," Drug Safety, vol. 33, no. 9, pp. 727-740, 2010.

[17] F. Kajbaf and J. Lalau, "The prognostic value of blood pH and lactate and metformin concentrations in severe metforminassociated lactic acidosis," BMC Pharmacology and Toxicology, vol. 14, article 22, 2013.

[18] C. Briet, M. Saraval-Gross, F. Kajbaf, A. Fournier, L. Hary, and J. D. Lalau, "Erythrocyte metformin levels in patients with type 2 diabetes and varying severity of chronic kidney disease," Clinical Kidney Journal, vol. 5, pp. 65-67, 2012.

[19] J. Lalau and C. Lacroix, "Measurement of metformin concentration in erythrocytes: clinical implications," Diabetes, Obesity and Metabolism, vol. 5, no. 2, pp. 92-98, 2003.

[20] A. S. Levey, J. Coresh, T. Greene et al., "Using standardized serum creatinine values in the modification of diet in renal disease study equation for estimating glomerular filtration rate," Annals of Internal Medicine, vol. 145, no. 4, pp. 247-254, 2006.

[21] M. F. Holick, "Vitamin D: a D-Lightful health perspective," Nutrition Reviews, vol. 66, supplement 2, pp. S182-S194, 2008.

[22] C. Lacroix, P. Danger, and F. Wojciechowski, "Microassay of plasma and erythrocyte metformin by high-performance liquid chromatography," Annales de Biologie Clinique, vol. 49, no. 2, pp. 98-101, 1991.

[23] N. G. Forouhi, J. Luan, A. Cooper, B. J. Boucher, and N. J. Wareham, "Baseline serum 25-hydroxy vitamin $\mathrm{d}$ is predictive of future glycemic status and insulin resistance the medical research council ely prospective study 1990-2000," Diabetes, vol. 57, no. 10, pp. 2619-2625, 2008.

[24] M. M. Soric, E. T. Renner, and S. R. Smith, "Effect of daily vitamin D supplementation on HbAlc in patients with uncontrolled 
type 2 diabetes mellitus: a pilot study," Journal of Diabetes, vol. 4, no. 1, pp. 104-105, 2012.

[25] A. M. Ali, T. G. Awad, and O. M. Ali, "Effect of short-term vitamin D supplementation on glycemic control in newly- diagnosed type 2 diabetics," Australian Journal of Basic and Applied Sciences, vol. 5, no. 6, pp. 1235-1239, 2011.

[26] G. Zoppini, A. Galletti, G. Targher et al., "Glycated hemoglobin is inversely related to serum vitamin D levels in type 2 diabetic patients," PLoS ONE, vol. 8, Article ID e82733, 2013.

[27] W. G. Tsiaras and M. A. Weinstock, "Factors influencing vitamin d status," Acta Dermato-Venereologica, vol. 91, no. 2, pp. 115-124, 2011.

[28] J. A. Hirst, A. J. Farmer, R. Ali, N. W. Roberts, and R. J. Stevens, "Quantifying the effect of metformin treatment and dose on glycemic control," Diabetes Care, vol. 35, no. 2, pp. 446-454, 2012.

[29] H. Pham, K. M. Utzschneider, and I. H. De Boer, "Measurement of insulin resistance in chronic kidney disease," Current Opinion in Nephrology and Hypertension, vol. 20, no. 6, pp. 640-646, 2011.

[30] Q. Li, Y. Ju, T. Jin et al., "Haemoglobin $A_{1 c}$ measurement in patients with chronic kidney disease," Clinical Biochemistry, vol. 47, no. 6, pp. 481-484, 2013.

[31] J. Ly, R. Marticorena, and S. Donnelly, "Red blood cell survival in chronic renal failure," The American Journal of Kidney Diseases, vol. 44, no. 4, pp. 715-719, 2004.

[32] S. Nurko, "Anemia in chronic kidney disease: causes, diagnosis, treatment," Cleveland Clinic Journal of Medicine, vol. 73, no. 3, pp. 289-297, 2006.

[33] N. Selvaraj, Z. Bobby, and M. G. Sridhar, "Increased glycation of hemoglobin in chronic renal failure potential role of oxidative stress," Archives of Medical Research, vol. 39, no. 3, pp. 277-284, 2008. 


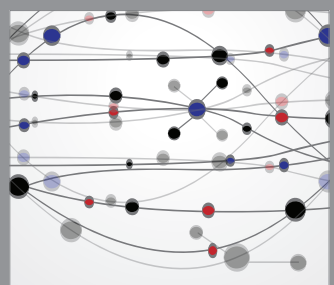

The Scientific World Journal
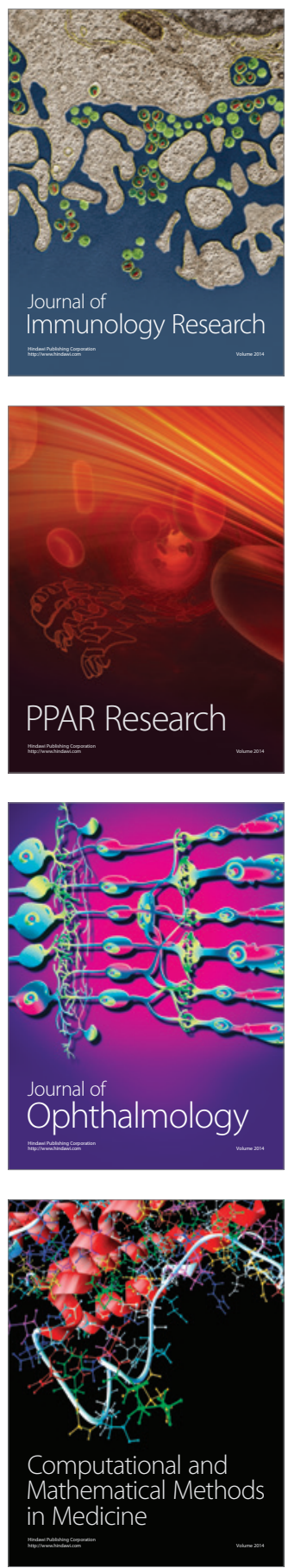

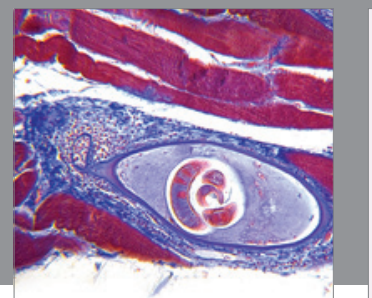

Gastroenterology

Research and Practice
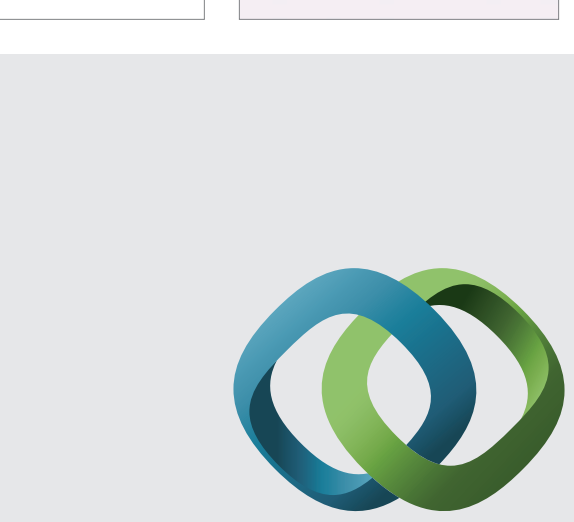

\section{Hindawi}

Submit your manuscripts at

http://www.hindawi.com
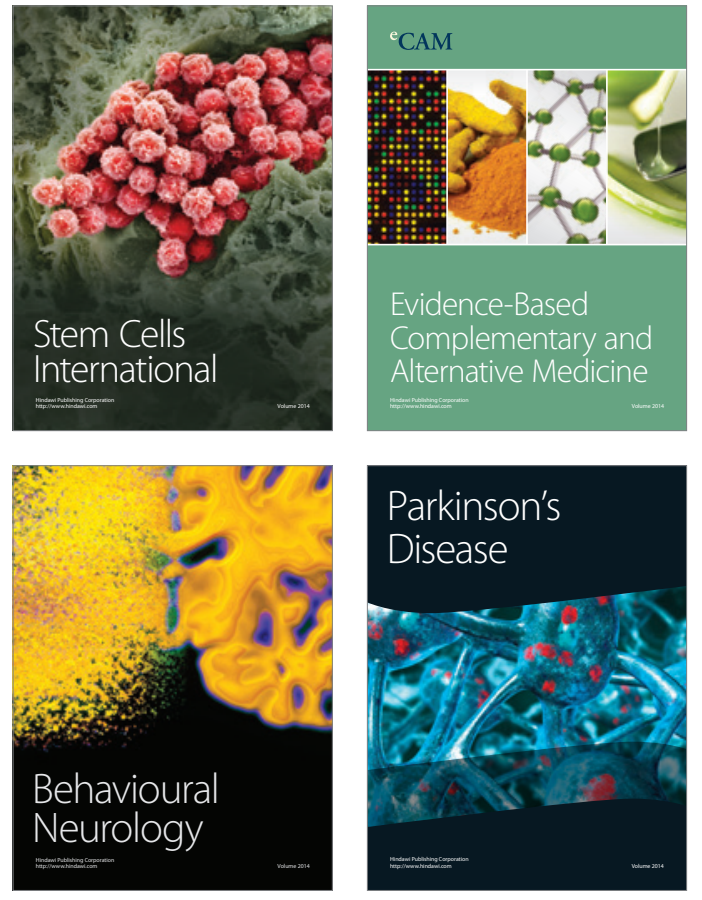
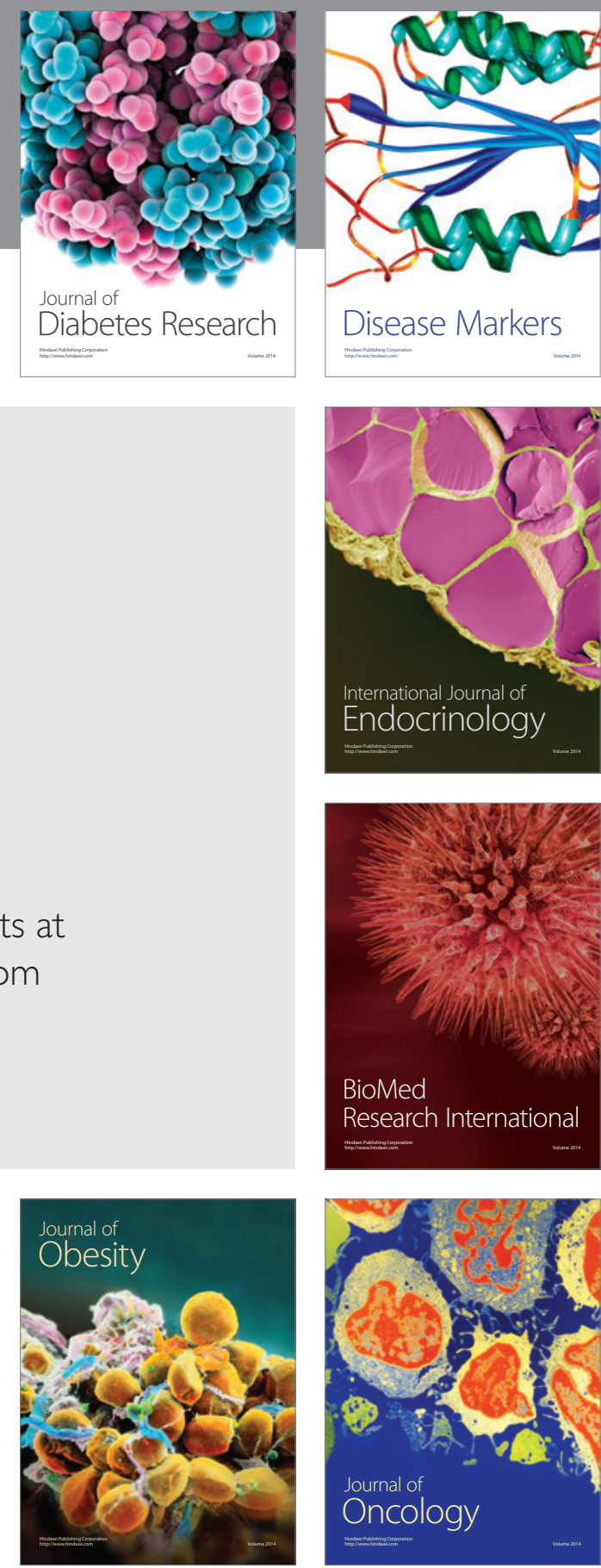

Disease Markers
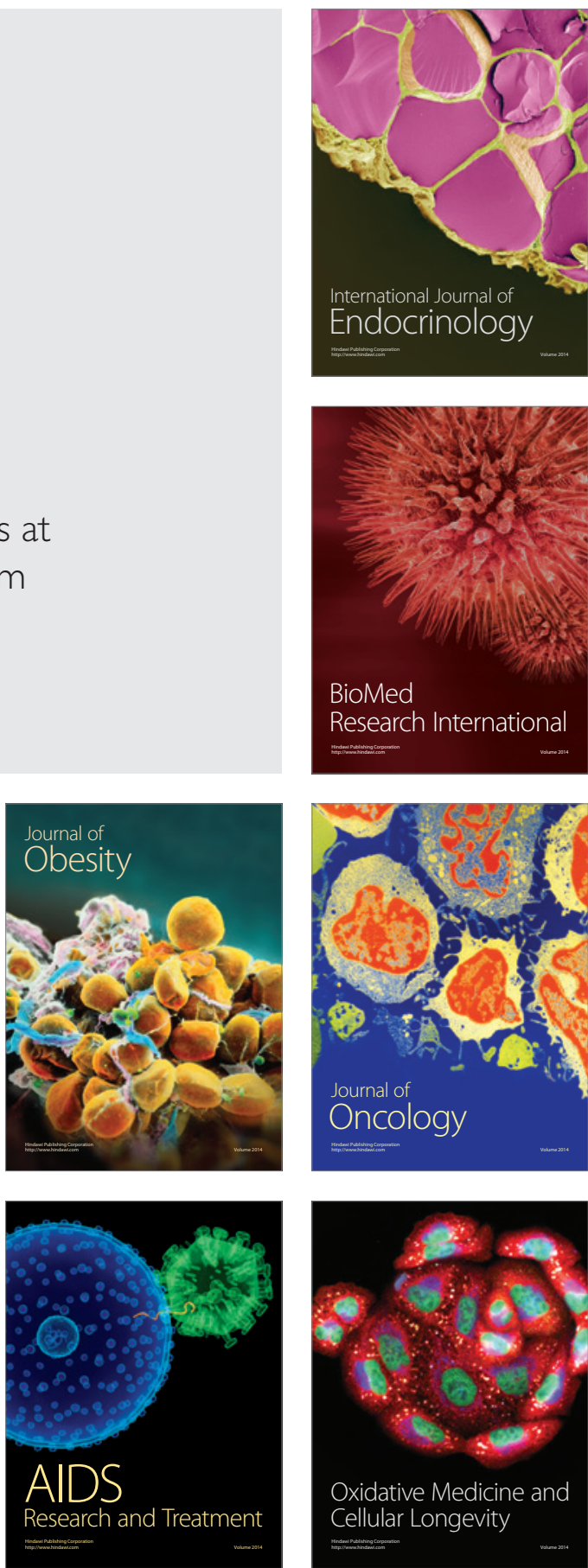